\title{
Rac1 regulates heat shock responses by reorganization of vimentin filaments: Identification using MALDI-TOF MS
}

\author{
S-Y Lee ${ }^{1}$, EJ Song ${ }^{1}$, H-J Kim ${ }^{1}$, H-J Kang ${ }^{1}$, J-H Kim² ${ }^{2}$ and \\ K-J Lee L, $^{\star 1}$ \\ 1 The Center for Cell Signaling Research, Division of Molecular Life Sciences and \\ College of Pharmacy, Ewha Womans University, Seoul, 120-750, Korea \\ 2 Department of Life Science, Kwangju Institute of Science and Technology, \\ Kwangju 506-712, Korea \\ * Corresponding author: K-J Lee, Division of Molecular Life Sciences and \\ College of Pharmacy, Ewha Womans University, Seoul 120-750, Korea \\ Tel: 82-2-3277-3038; Fax: 82-2-3277-3760; E-mail: kj@@m.ewha.ac.kr
}

Received 5.1.01; revised 16.5.01; accepted 11.6.01

Edited by G Melino

\begin{abstract}
Rac1 has been implicated in a wide variety of biological processes, including actin remodeling and various signaling cascades. Here we have examined whether Rac1 might be involved in heat shock-induced cell signaling. We found that Rat2 stable cells expressing a dominant negative Rac1 mutant, RacN17 (Rat2-RacN17), were significantly more tolerant to heat shock than control Rat2 cells, and simultaneously inhibited the activation of SAPK/JNK by heat shock compared to control Rat2 cells. However, no discernible effect was observed in typical heat shock responses including total protein synthesis and heat shock protein synthesis. To identify the proteins involved in this difference, we separated the proteins of both Rat2 and Rat2-RacN17 cell lines after heat shock using two-dimensional gel electrophoresis and identified the differentially expressed proteins by matrix assisted laser desorption/ionization time of flight mass spectrometry (MALDI-TOF MS) after in-gel trypsin digestion. Differentially expressed proteins between two cell lines were identified as vimentin. Rat2-RacN17 cells showed significant changes in vimentin as well as marked changes in vimentin reorganization by heat shock. The vimentin changes were identified as $\mathrm{N}$-terminal head domain cleavage. These results suggest that Rac1 plays a pivotal role in the heat shockinduced signaling cascade by modifying intermediate vimentin filaments. Cell Death and Differentiation (2001) 8, 1093-1102.
\end{abstract}

Keywords: heat shock; Rac1; vimentin; MALDI-TOF MS; SAPK/ JNK activation; thermotolerance

Abbreviations: HSF, heat shock factor; HSP, heat shock protein; SAPK, stress-activated protein kinase; JNK, c-Jun N-terminal kinase; GST, glutathione-S-transferase; PARP, poly(ADP-ribose) polymerase; SRF, serum response factor; TNF, tumor necrosis factor; MALDI-TOF MS, matrix assisted laser desorption/ionization time of flight mass spectrometry

\section{Introduction}

Heat shock responses have been studied extensively because they are remarkably well-conserved phenomena from bacteria to mammals. Modest elevations of temperature induce apoptotic cell death. An initial, nonlethal heat dose can induce temporary resistance against subsequent lethal heat exposure. This phenomenon is called thermotolerance. ${ }^{1}$ Thermotolerant cells induce the overexpression of a family of heat shock proteins (HSPs) and are protected from cellular death caused by heat shock, oxidative stresses, hypoxia, amino acid analogs, and sodium arsenite. ${ }^{2}$ Therefore, this suggests that the chaperonic function of hsps is associated with the development of thermotolerance. .,4 $^{3,4}$

However, the molecular events by which heat shock transduces signals into cellular responses such as a transient blockage of protein synthesis, changes in nuclear and other organelle structures and cytoskeletal changes are not well defined. Although many reports have shown that heat shock activates SAPK/JNKs, p38/HOG1 kinase, hsps, caspases and heat shock factor (HSF), it is not known which upstream signaling molecules are activated by heat shock and how they regulate these downstream targets.

Several lines of evidence suggest that Rac1 may have a role as an upstream molecule of stress responses. Rac1 is a small GTP-binding protein of the Rho family, a subset of the Ras superfamily. It acts as a molecular switch to control various cellular processes by shuttling between an active GTP-bound form, and an inactive GDP-bound form. ${ }^{5}$ Rac1 proteins have been linked to the regulation of a wide variety of cellular processes including actin reorganization, especially membrane ruffles and lamellipodia induced by growth factor or activated Ras. Also, Rac1 is a key regulator of the superoxidegenerating NADPH oxidase in phagocytes ${ }^{6}$ and activates the transactivation factors such as serum response factor $(\mathrm{SRF})^{7}, \mathrm{Jun}^{8,9}$ and nuclear transcription factor- $\kappa \mathrm{B}$ (NF$\kappa \mathrm{B}) .{ }^{10}$ The activation of Jun is mediated by SAPK/JNK that phosphorylates the transactivation domain of Jun. Several groups have demonstrated that Rac1 can regulate the activation of JNK. ${ }^{11}$ Expression of constitutively active mutants of Rac1 in HeLa, NIH3T3, and COS cells resulted in a stimulation of $\mathrm{JNK}^{8}$ In agreement, the dominant-negative mutant, RacN17, blocked JNK activation by EGF and $\mathrm{TNF}_{\alpha}{ }^{9}$ Strong activation of SAPK/JNK is induced by inflammatory cytokines, tumor necrosis factor $\alpha(\mathrm{TNF} \alpha)$, interleukin-1 $\beta$ (IL-1 $\beta)$, and a diverse array of cellular stresses such as heat shock, UV, and ionizing radiation. ${ }^{12}$ It has been proposed that cellular functions of SAPK/JNK mediate growth arrest, apoptosis, or activation of immune responses. In addition, Rac1 has been implicated in invasion by T-cell lymphoma ${ }^{13}$ and cell cycle progression through $\mathrm{G} 1 .^{14}$ 
Most investigations suggest that Rac1 mediates the responses triggered by growth factors such as PDGF, EGF, NGF, insulin, etc. ${ }^{15} \mathrm{~A}$ few reports imply that Rac1 is involved in the apoptosis induced by death ligands such as fas ligand ${ }^{16}$ and TNF $\alpha{ }^{17}$ Almost nothing is known about the correlation between Rac1 and environmental stresses, although many studies have shown that Rac1 controls the activity of SAPK/JNK which is strongly activated by environmental stresses. Recent reports showed that heat shock-induced cell death could be mediated by PAK2, a serine/threonine kinase that is activated by Rac1 and Cdc $42^{18}$ and Rac1 regulated stress-induced, redox-dependent HSF activation. ${ }^{19}$ These suggest that Rac1 may act as a mediator inducing stress induced cell death.

Here we have examined whether Rac1 is involved in the heat shock signaling pathway using rat fibroblast cells (Rat2) and its stable cell line expressing the dominant negative Rac mutant, RacN17 (Rat2-RacN17) in which Rac1 is not activated by any stimuli. Cellular heat shock responses were investigated in both Rat2 and Rat2RacN17 cells by measuring cell survival, protein synthesis, hsp70 induction, caspase-3 activity, SAPK/JNK activation and decay, and protein profiles. We found that Rat2RacN17 cells were more tolerant to heat shock than control Rat2 cells. This tolerance was not the result of typical heat shock responses including heat shock protein synthesis and protein synthesis recovery, but rather the fast recovery of cytoskeletal collapse by heat shock. To identify the molecules that may be involved in cytoskeletal changes, cellular protein profile changes in both cell lines by heat shock were examined by MALDI-TOF MS. Significant changes between the two cells were observed in the intermediate filament vimentin in response to heat shock. This suggests that Rat2-RacN17 cells could become thermotolerant by modulating the reorganization of vimentin. These findings show that Rac1 has the potential to be involved in heat shock-induced cell death by modifying cytoskeletal protein changes and triggering the partial activation of SAPK/JNK.

\section{Results}

\section{Rat2-RacN17 cells are more resistant to heat shock than Rat2 cells}

To determine whether Rac1 might be involved in heat shockinduced cell death, we first examined cell survival after heat shock in control Rat2 and Rat2-RacN17 cells with stable expression of the dominant negative Rac1 mutant, RacN17. Control Rat2 and Rat2-RacN17 cells were subjected to heat shock at $45^{\circ} \mathrm{C}$ for various lengths of time and recovered at $37^{\circ} \mathrm{C}$ for $48 \mathrm{~h}$. After each treatment, cell survival was determined by SRB assay (Figure 1). Survival differences between the two cell lines increased in a heat dosedependent manner. Rat2-RacN17 cells were more resistant to heat shock than Rat2 cells. Several Rat2-RacN17 clones showed similar results (data not shown).

Heat shock-induced cell death was assessed by flow cytometric analysis of apoptotic fractions after propidium iodide staining following exposure of Rat2 and Rat2-

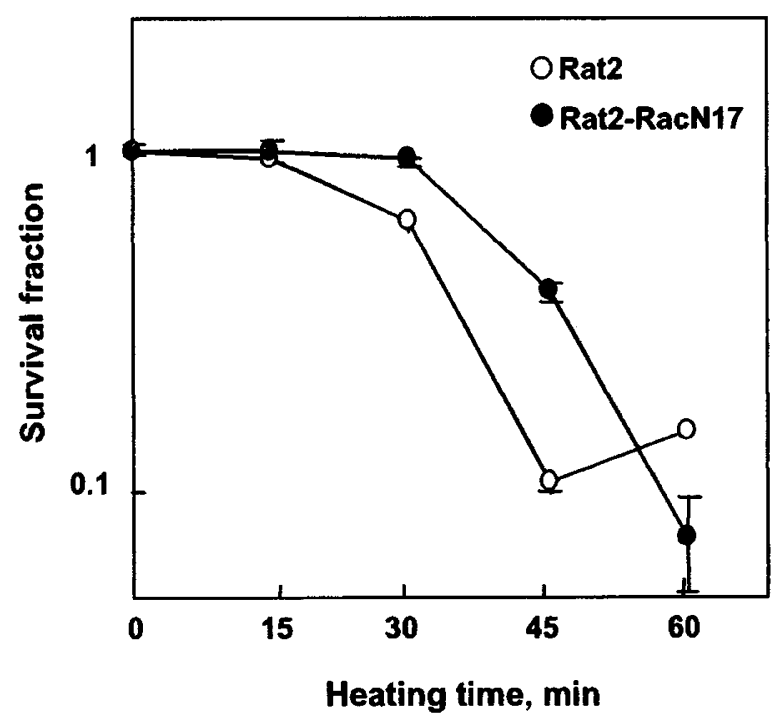

Figure 1 Effect of Rac1 negative mutant on cell survival after heat shock. Control Rat2 (O) and Rat2-RacN17 (O) cells were exposed to heat shock at $45^{\circ} \mathrm{C}$ for various lengths of time $(0,15,30,45$ and $60 \mathrm{~min})$ and recovered at $37^{\circ} \mathrm{C}$ for $48 \mathrm{~h}$. Cell survival was monitored by SRB assay

RacN17 cells to heat shock at $45^{\circ} \mathrm{C}$ for various lengths of time and recovery at $37^{\circ} \mathrm{C}$ for $24 \mathrm{~h}$. The apoptotic fraction was significantly reduced in Rat2-RacN17 cells (Figure 2), which was also confirmed with immunofluorescence microscopy (data not shown).

Heat resistance of Rat2-RacN17 cells was again confirmed by measuring caspase-3 activity. Both of activation of procaspase-3 and cleavage of its substrate PARP by caspase- 3 were detected $48 \mathrm{~h}$ after heat shock. As shown in Figure 3, activation of procaspase-3 and cleavage of PARP by caspase- 3 after heat shock at $45^{\circ} \mathrm{C}$ for 45 min was significantly reduced in Rat2-RacN17 cell. These results suggest that RacN17 prevents heat shockinduced cell death, therefore Rac1 is required for the heat shock-induced apoptotic pathway.

\section{No differences in typical heat shock responses were observed in Rat2 and Rat2-RacN17 cells}

Next we carried out metabolic labeling for newly synthesized proteins to determine whether thermotolerance of Rat2-RacN17 cells was related to typical heat shock responses including protein synthesis blockage and recovery, and heat shock protein synthesis. It is well known that overexpression of heat shock proteins (HSPs) prevents cell death induced by various stresses and induces rapid recovery from the stresses. The rate of protein synthesis was monitored by ${ }^{35} \mathrm{~S}$-methionine pulse labeling during recovery after heat shock (Figure 4). Cells were exposed to various amounts of heat shock at $45^{\circ} \mathrm{C}$ for $10-30 \mathrm{~min}$, allowed to recover at $37^{\circ} \mathrm{C}$ for various lengths of time, and then labeled with ${ }^{35} \mathrm{~S}$-methionine for $1 \mathrm{~h}$ at $37^{\circ} \mathrm{C}$ to measure the protein synthesis rates. Equal amounts of proteins were applied on each lane for SDSPAGE. As shown in Figure 4 , heating at $45^{\circ} \mathrm{C}$ immediately 


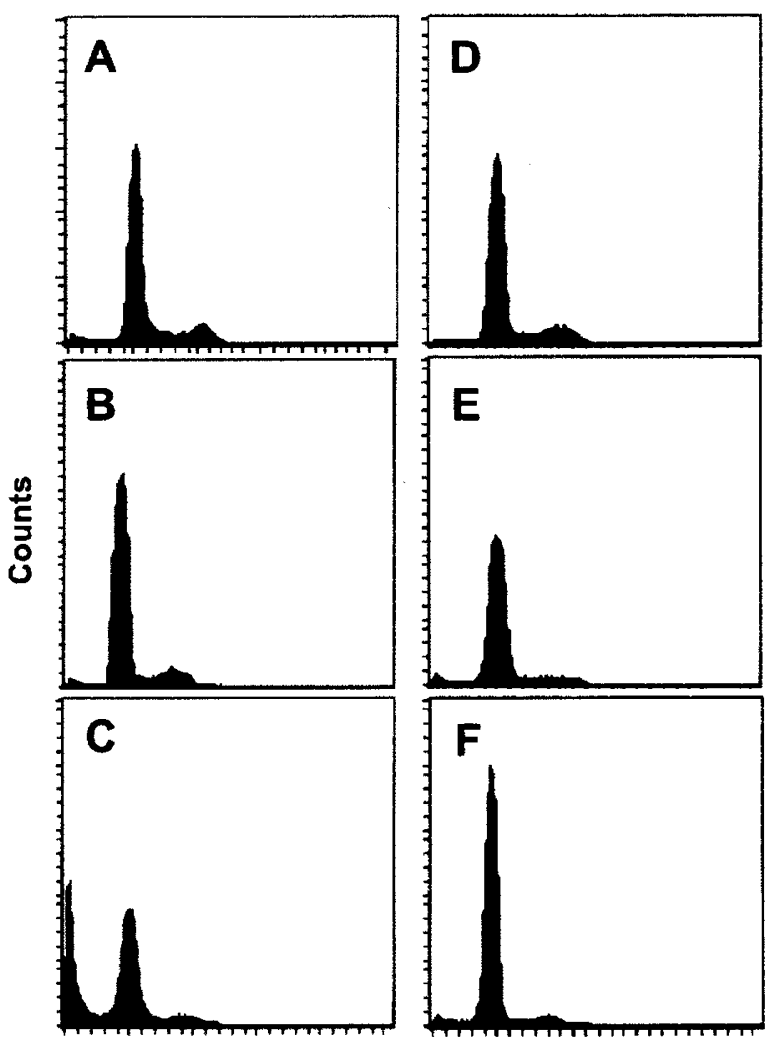

FL2-A

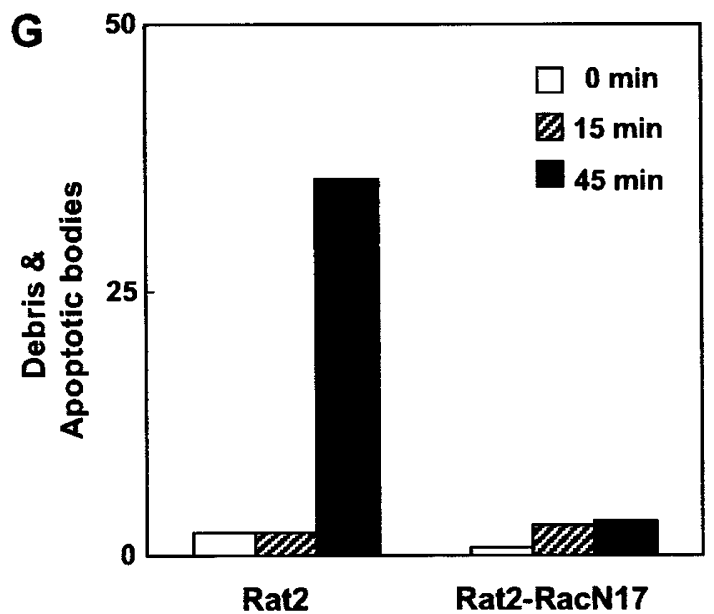

Figure 2 Effect of Rac1 negative mutant on cell death after heat shock. Control Rat2 (A, B, C) and Rat2-RacN17 (D, E, F) cells were exposed to heat at $45^{\circ} \mathrm{C}$ for $0 \mathrm{~min}(\mathbf{A}, \mathbf{D}), 15 \mathrm{~min}(\mathrm{~B}, \mathrm{E})$ and $45 \mathrm{~min}(\mathbf{C}, \mathbf{F})$ and recovered for $48 \mathrm{~h}$. Cell death was monitored by flow cytometric analysis after propidium iodide staining and the apoptotic fraction was quantified in $(\mathbf{G})$

blocked total protein synthesis, but synthesis was restored gradually during recovery at $37^{\circ} \mathrm{C}$. The kinetics of inhibition and recovery were dependent on the extent of the heat shock stress. However, no discernible differences in the rate of protein synthesis were observed between Rat2 and Rat2-RacN17 cells (Figure 4) compared to the apoptotic differences shown in Figures 1-3.

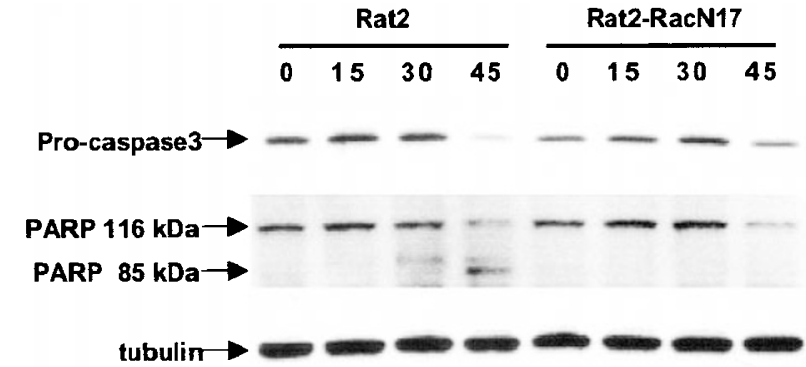

Figure 3 Caspase-3 activities in Rat2 and Rat2-RacN17 cells after heat treatment. Cells were exposed to $45^{\circ} \mathrm{C}$ for 0,15 and $45 \mathrm{~min}$ and recovered at $37^{\circ} \mathrm{C}$ for $48 \mathrm{~h}$. Activation of procaspase- 3 , cleavage of PARP by caspase- 3 and tubulin as a loading control were measured by Western blotting using anticaspases-3, anti-PARP and anti-tubulin antibodies

A

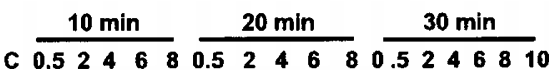

帮

B

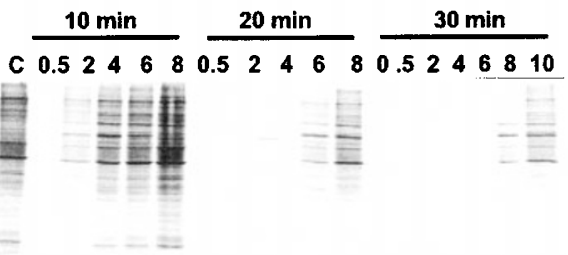

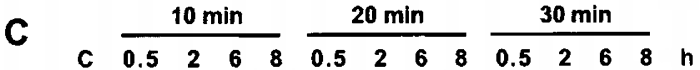

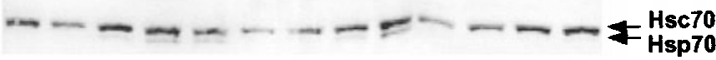

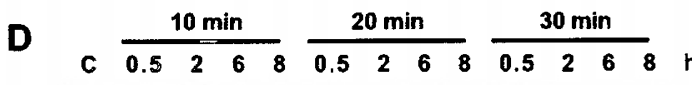

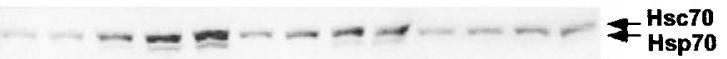

Figure 4 Newly synthesized protein profile (A, B) and hsp70 level (C, D) after heat shock treatment. Rat2 ( $\mathbf{A}$ and $\mathbf{C})$ and Rat2-RacN17 (B and $\mathbf{D})$ cells were exposed to heat shock at $45^{\circ} \mathrm{C}$ for 10,20 and $30 \mathrm{~min}$ and then recovered for $0.5,2,4,6$ and $8 \mathrm{~h}$. Newly synthesized proteins were then pulse labeled with ${ }^{35} \mathrm{~S}$-methionine for $1 \mathrm{~h}$. The same amount of protein samples were separated on $12 \%$ SDS-PAGE and detected by BAS 2500 . Hsp70 was detected by Western analysis using monoclonal antibody recognizing both cognate and inducible hsp70

We examined the levels of inducible hsp70 to determine whether Rac1 is related to hsp70 induction in control Rat2 and Rat2-RacN17 cells during recovery after heat shock at $45^{\circ} \mathrm{C}$. Hsp70 is known as a key molecule in protecting cells from heat shock-induced cell death. However, no discernible difference of inducible hsp70 (Figure 4) and hsp27 (data not shown) between control Rat2 and Rat2-RacN17 
cells was observed. The results suggest that the expression of hsps is not solely responsible for the heat shock resistance of Rat2-RacN17 cells. Further investigations are needed to determine how Rat2-RacN17 cells are made more insensitive to heat.

\section{Rac1 is involved in SAPK/JNK activation in response to heat shock}

SAPK/JNK is activated by exposure of cells to heat shock. Rac1 regulates the activation of the SAPK/JNK cascade induced by EGF and TNF $\alpha$ in certain cell types. ${ }^{9}$ Also, it has been proposed that activation of SAPK/JNK is required for cell death induced by various stresses. It is possible that Rat2-RacN17 cells could prevent cell death in response to heat shock by suppressing SAPK/JNK activation. To test this hypothesis, the cellular activities of SAPK/JNK were measured in response to heat shock in both Rat2 and Rat2RacN17 cell lines. Cells were heated at $45^{\circ} \mathrm{C}$ for $0,15,30$, 45 and $60 \mathrm{~min}$ and harvested within $20 \mathrm{~min}$ after heat shock. The SAPK/JNK activity was measured by in vitro kinase assay using GST-c-Jun fusion protein as a substrate. SAPK/JNK was activated in a dose-dependent manner immediately after heat treatment. The SAPK/JNK activity of Rat2 cells was higher than that of Rat2-RacN17 cells in all cases (Figure 5A). The dominant negative Rac1 mutant, RacN17, showed reduced activation of SAPK/JNK in response to heat shock (Figure $5 \mathrm{~A}$ ). This suggests that Rat2-RacN17 cells are more insensitive to heat shock by inhibiting SAPK/JNK activation.

The kinetics of SAPK/JNK activity were measured in cells exposed to the elevated temperature and during recovery at $37^{\circ} \mathrm{C}$ (Figure 5B). After heat shock treatment at $45^{\circ} \mathrm{C}$ for $30 \mathrm{~min}$, maximal SAPK/JNK activity was detected after $4 \mathrm{~h}$ recovery in Rat2 cells and $2 \mathrm{~h}$ recovery in Rat2RacN17 cells (Figure 5B). Maximum amplitude of SAPK/ JNK activity during the recovery after heat shock at $45^{\circ} \mathrm{C}$ for 30 min in Rat2 cells was about twofold larger than in Rat2-RacN17 cells. The recovery time to reach maximal activity of SAPK/JNK was shorter in Rat2-RacN17 cells than Rat2 cells. In other words, Rat2-RacN17 cells operate inactivation devices slightly faster than Rat2 cells. Accordingly, Rac1 mediates SAPK/JNK activation in response to heat shock.

\section{Differentially expressed proteins in Rat2 and Rat2- RacN17 cells by heat shock were identified}

To investigate the differentially expressed proteins after heat shock between Rat2 and Rat2-RacN17 cells, protein profiles were examined with two-dimensional gel electrophoresis. Control Rat2 (Figure 6A) and Rat2-RacN17 (Figure 6B) cells were exposed to heat shock at $45^{\circ} \mathrm{C}$ for $20 \mathrm{~min}$ and recovered at $37^{\circ} \mathrm{C}$ for $8 \mathrm{~h}$ (Figure 6C,D). Then both cells were metabolically labeled with ${ }^{35} \mathrm{~S}$-methionine at $37^{\circ} \mathrm{C}$ for $1 \mathrm{~h}$. Differentially expressed protein spots between Rat2 and Rat2-RacN17 cells are represented with arrowheads in Figure 6. The expression of proteins indicated with arrowhead 1 was remarkably reduced in Rat2-RacN17 cells. Proteins 3, 4, 5 and 6 were highly
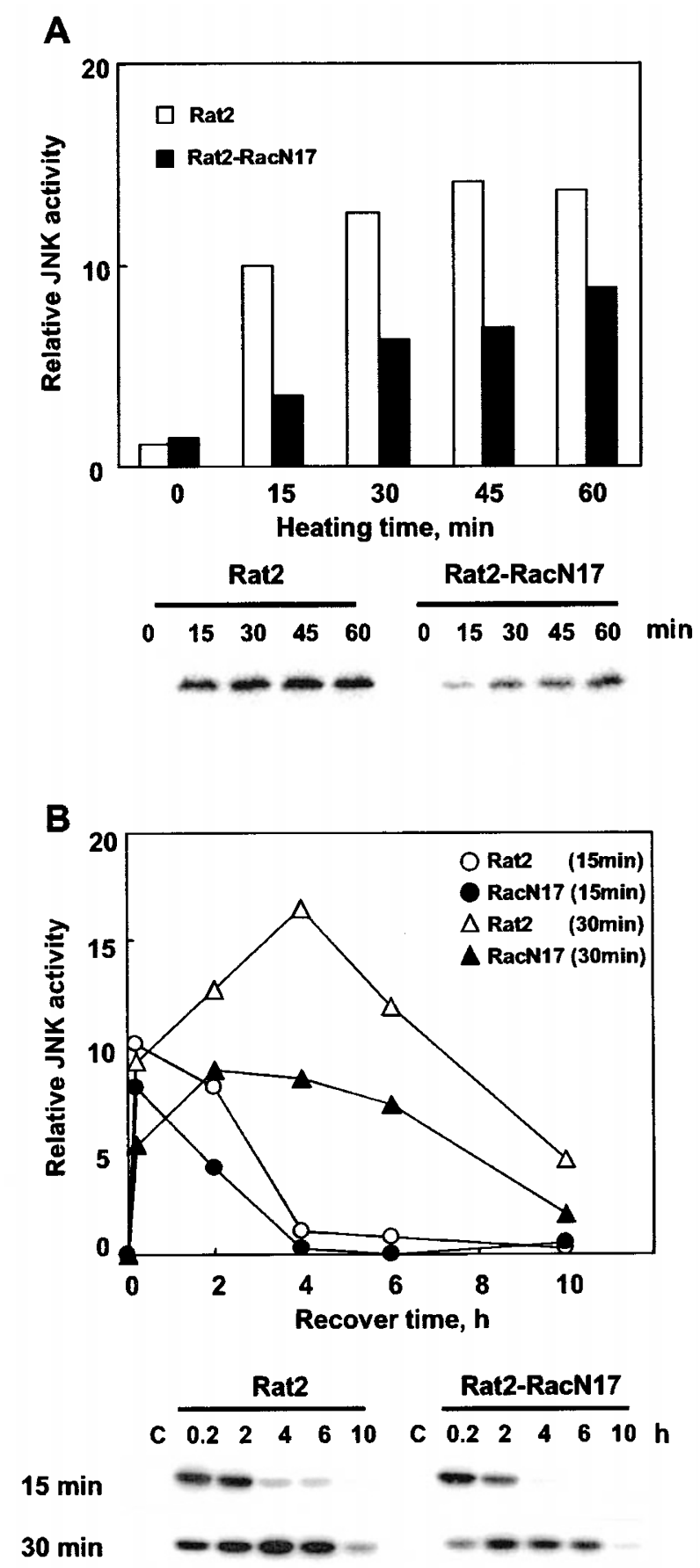

Figure 5 Kinetics of SAPK/JNK activation depending on the amount of heat shock stress $(\mathbf{A})$ and the activation and decay kinetics of SAPK/JNK during recovery after heat shock (B). (A) Rat2 (white bar) and Rat2-RacN17 (black bar) were exposed to heat shock at $45^{\circ} \mathrm{C}$ for $0,15,30,45$ and 60 min and the activation of SAPK/JNK was measured immediately after heat shock. (B) Rat2 $(O, \triangle)$ and Rat2-RacN17 $(\boldsymbol{O}, \boldsymbol{\Delta})$ cells were exposed to heat shock at $45^{\circ} \mathrm{C}$ for $15 \mathrm{~min}(\mathrm{O}, \mathbf{O})$ and $30 \mathrm{~min}(\triangle, \mathbf{\Delta})$ and recovered at $37^{\circ} \mathrm{C}$ for $0.2,2,4,6$ and $10 \mathrm{~h}$, then SAPK/JNK activity was measured at each time point

expressed in Rat2-RacN17 cells in comparison to Rat2 cells. The differences were amplified during recovery after heat shock. Spot 1 was increased by heat shock in Rat2 
A

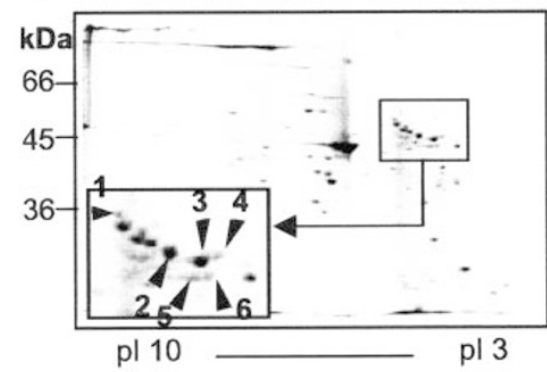

C

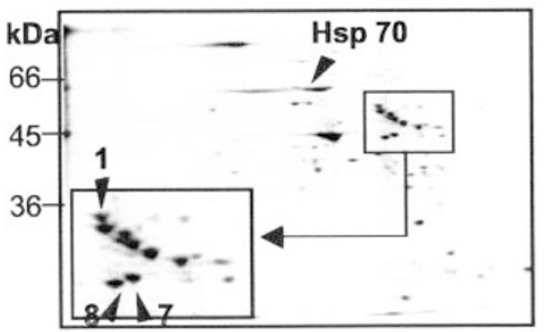

pl 10

pl 3
B

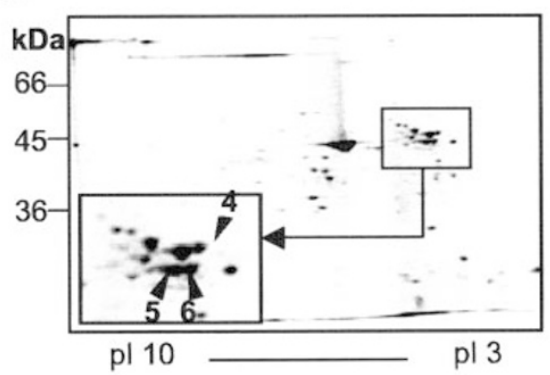

D

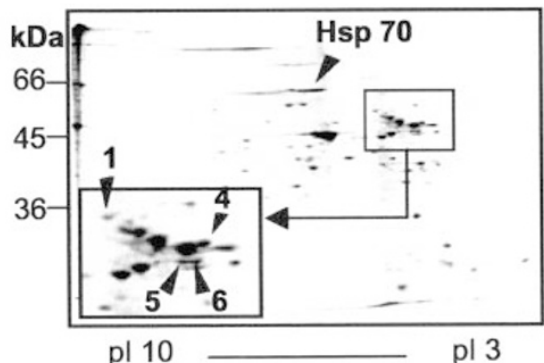

Figure 6 Newly synthesized protein profiles on two-dimensional gel electrophoresis after heat shock. Rat2 (A, C) and Rat2-RacN17 (B, D) cells were exposed to heat shock at $45^{\circ} \mathrm{C}$ for $20 \mathrm{~min}$, recovered at $37^{\circ} \mathrm{C}$ for $8 \mathrm{~h}$ and then pulse labeled with ${ }^{35} \mathrm{~S}$-methionine for $1 \mathrm{~h}(\mathbf{C}, \mathbf{D})$. A and $\mathbf{B}$ samples were from control cells without heat treatment. The same amount of total proteins was applied and separated on two-dimensional gel electrophoresis and radioactivity levels detected with BAS

cells, but not in Rat2-RacN17 cells and spots 7 and 8 were produced by heat shock regardless to the cell line. These spots may be the key molecules regulated by Rac1 after heat shock.

We have identified each spot by peptide fingerprinting using MALDI-TOF MS after in-gel trypsinization. The protein spots were excised and proteins were in-gel digested with trypsin. The digested mixtures were eluted from gels, concentrated, and analyzed by MALDI-TOF MS. Mass spectra of peptides were aligned on the map with the database as described in Materials and Methods. It emerged that spots $1,2,3,4,5$ and 6 were components of the intermediate filament vimentin (Figure 7, Table 1). The main differences were found in vimentin spots 3, 4, 5 and 6 between control Rat2 and Rat2-RacN17 cell and in vimentin spot 1 with and without heat treatment. The molecular modification changes of various vimentin spots have been determined. Based on the molecular mass of the peptide fragments, spot 1 was identified as full vimentin and spots 2, 3, 4, 5 and 6 were serially $\mathrm{N}$-terminal deleted vimentin as shown in Table 2. The existence of various vimentin spots was confirmed by Western analysis using vimentin antibody and $\mathrm{N}$-terminal head domain specific vimentin antibody (Figure 8). The results were consistent with peptide mapping data using MALDI-TOF MS; spots 1 and 2 contain the head domain, and spots $3,4,5,6$ were $\mathrm{N}$-terminal truncated vimentin. It is possible that the resistance to heat shock in Rat2-RacN17 cells may be related to these modifications of vimentin.

\section{Heat shock causes the redistribution of intermediate vimentin filaments reversibly}

We then examined the heat shock effect on the localization of vimentin filaments. Both Rat2 and Rat2-RacN17 cells were treated with heat shock at $45^{\circ} \mathrm{C}$ for $20 \mathrm{~min}$ and recovered at $37^{\circ} \mathrm{C}$ for $0,3,8$ and $24 \mathrm{~h}$. At each time point, cells were simultaneously stained with propidium iodide for nucleus and anti-vimentin antibody as shown in Figure 9. The fine fibrillar vimentin network collapsed and concentrated around the nucleus immediately after heat shock (Figure 9B,G). During the recovery at $37^{\circ} \mathrm{C}$, significant differences between control Rat2 cells and Rat2-RacN17 cells were observed. After $3 \mathrm{~h}$, the vimentin network in Rat2 cells penetrated into the nucleus, while in Rat2RacN17 cells it remained around the periphery (Figure $9 \mathrm{C}, \mathrm{H})$. After $8 \mathrm{~h}$, the vimentin filaments in Rat2 cells showed redistribution to one side of the nucleus (Figure 9D), while in Rat2-RacN17 cells they recovered to normal (Figure 9l). After $24 \mathrm{~h}$, the vimentin network returned to normal in both cells (Figure 9E,J). The Rac1 negative mutant (RacN17) showed reduced damage to the vimentin network induced by heat shock. Thus, this data shows that Rac1 plays an important role in reversible reorganization of vimentin induced by heat shock.

\section{Discussion}

Here we demonstrate that Rac1 is involved in the heat shockinduced apoptotic signaling pathway. Rat2-RacN17 cells 


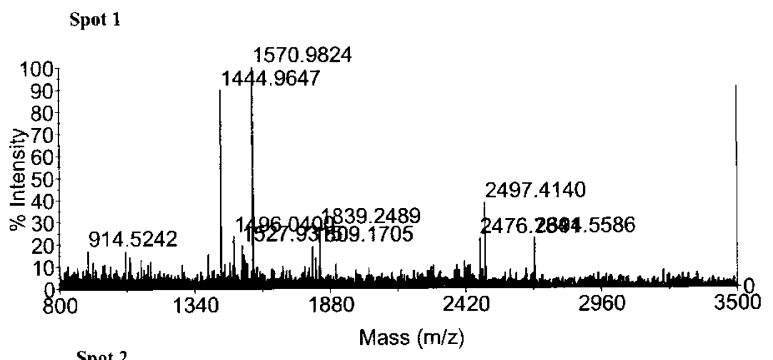

Spot 2

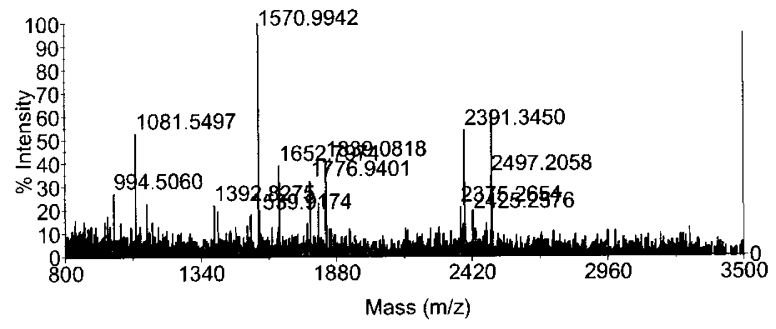

Spot 3

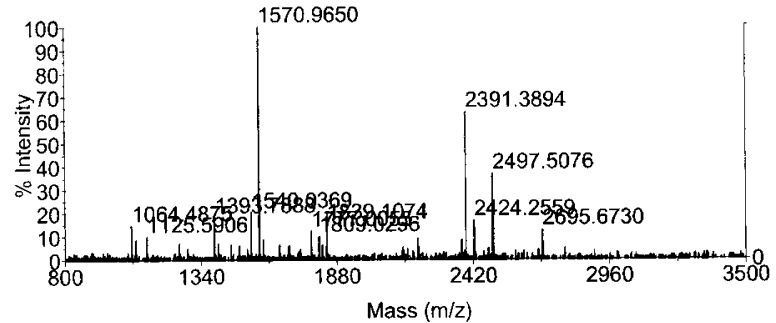

Spot 4

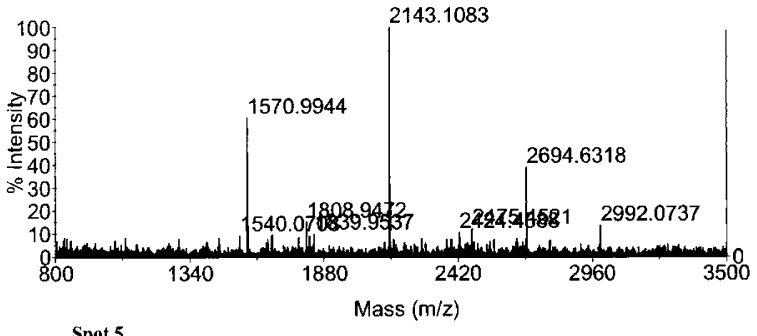

Spot 5

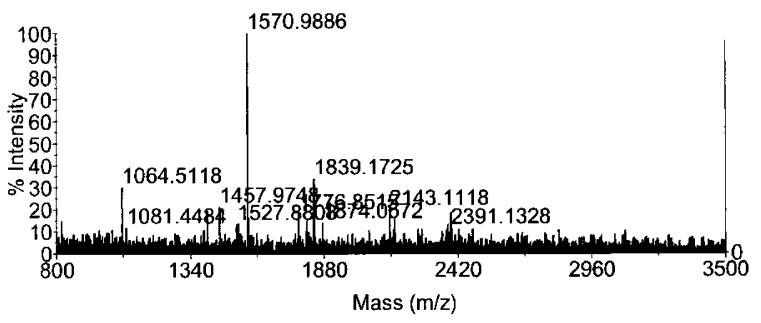

Spot 6

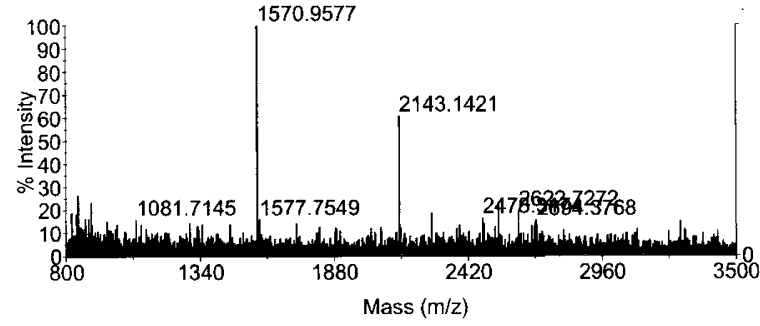

Figure 7 MALDI-TOF MS spectra of peptides obtained by in-gel trypsin digestion of various vimentin spots (spots $1-6$ ) expressed differentially between Rat2 and Rat2-RacN17 cells and between control and heat treated cells. Spot numbers were identical to those in Figure 6

Table 1 Protein identification of each spot in Figure 6 by peptide fingerprinting using MALDI-TOF MS

\begin{tabular}{llcccc}
\hline Spot & $\begin{array}{c}\text { Identified } \\
\text { protein }\end{array}$ & $\begin{array}{c}\text { NCBI } \\
\text { entry }\end{array}$ & $\begin{array}{c}\text { Mass } \\
\text { (Da) }\end{array}$ & PI & $\begin{array}{c}\% \\
\text { sequence }\end{array}$ \\
\hline $1-6$ & Vimentin & 401365 & 53733.0 & 5.06 & $19-37$ \\
7 & HSP 70 & 415898 & 50405.1 & 5.59 & 21 \\
8 & HSC70-ps1 & 347019 & 70928.5 & 5.43 & 28 \\
\hline
\end{tabular}

expressing the Rac1 dominant negative mutant RacN17, showed reduced heat shock-induced cell death. This effect was not due to typical heat shock responses including protein synthesis blockage and repair and heat shock protein synthesis. Rather, vimentin reorganization by heat shock was more rapidly repaired in Rat2-RacN17 cells than in control Rat2 cells. Differential populations of vimentin were observed between Rat2 and Rat2-RacN17 cells and between control and heat shock treated cells. Thus, this is the first report to demonstrate the involvement of Rac1 in heat shock signaling by modifying vimentin.

The dominant negative mutant RacN17 was found to inhibit heat shock-induced cell death. Various aspects of this inhibitory mechanism were examined. No discernible differences in typical heat shock responses, including new synthesis of hsps and the recovery rate of protein synthesis after heat shock, were observed between control Rat2 and Rat2-RacN17 cells. These findings do not correspond well to the resistance of Rat2-RacN17 cells to heat shock, which leads to the question of which molecules are involved in the thermotolerance of Rat2-RacN17 cells.

We examined the activation of SAPK/JNK by heat shock in both cell lines. In Rat2-RacN17 cells, the activation of SAPK/JNK immediately after heat shock was reduced. The maximum extent of activation depending on the degree of heat stress was also lower and the decay kinetics of SAPK/JNK activation was faster than in control Rat2 cells. This finding indicates that Rac1 is involved in the activation of SAPK/JNK by heat shock as well as by fas ligand, $\operatorname{TNF} \alpha$, etc. ${ }^{8,17}$ The activation of SAPK/JNK has been recently shown to be an essential component of the signal transduction pathway which leads to programmed cell death in response to certain stimuli. ${ }^{20}$ Resistance to stress-induced cell death was examined in thermotolerant cells and in hsp70 overexpressing cells, which prevent the activation of SAPK/JNK. ${ }^{21,22}$ The kinetics of SAPK/JNK activation and decay is a marker of the extent of cell death and thermotolerance. ${ }^{23}$ The present results suggest that $\mathrm{RacN} 17$ may block the apoptotic pathway by reducing the activation of SAPK/ JNK regardless of the extent of hsp70 induction. This 
Table 2 Identification of peptide fragments in various vimentin spots (Figure 6) by MALDI-TOF MS

\begin{tabular}{|c|c|c|c|c|c|c|c|}
\hline $\begin{array}{l}\text { Peptide } \\
\text { fragment }\end{array}$ & $\begin{array}{c}\text { Calculated } \\
\mathrm{m} / \mathrm{z}\end{array}$ & $\begin{array}{c}\text { Spot } 1 \\
\text { Observed } \mathrm{m} / \mathrm{z}\end{array}$ & $\begin{array}{c}\text { Spot } 2 \\
\text { Observed } \mathrm{m} / \mathrm{z}\end{array}$ & $\begin{array}{c}\text { Spot } 3 \\
\text { Observed } \mathrm{m} / \mathrm{z}\end{array}$ & $\begin{array}{c}\text { Spot } 4 \\
\text { Observed } \mathrm{m} / \mathrm{z}\end{array}$ & $\begin{array}{c}\text { Spot } 5 \\
\text { Observed } \mathrm{m} / \mathrm{z}\end{array}$ & $\begin{array}{c}\text { Spot } 6 \\
\text { Observed } \mathrm{m} / \mathrm{z}\end{array}$ \\
\hline $29-36$ OR $29-36+P$ & 914.4583 & 914.5242 & 994.5060 & & & & \\
\hline $37-50$ & 1495.7869 & 1495.9107 & & & & & \\
\hline $51-64$ & 1444.7072 & 1444.9647 & & & & & \\
\hline $79-100$ & 2497.2575 & 2497.4140 & 2497.2058 & 2497.5076 & & & \\
\hline $82-100$ & 2143.0308 & & & & 2143.1083 & 2143.1118 & 2143.1421 \\
\hline $130-143$ & 1539.9110 & 1540.1533 & 1539.9174 & 1540.0370 & 1540.0708 & & \\
\hline $146-158$ & 1652.7954 & 1652.8910 & 1652.7974 & 1652.8542 & 1652.9386 & & \\
\hline $14-28$ OR $379-390$ & $\begin{array}{l}1527.6974 \\
1527.8284\end{array}$ & 1527.9315 & 1527.7029 & & & 1527.8808 & \\
\hline $411-424$ & 1570.9274 & 1570.9824 & 1570.9942 & 1570.9650 & 1570.9944 & 1570.9886 & 1570.9579 \\
\hline $425-440$ & 1838.9612 & 1839.2489 & 1839.0818 & 1839.1074 & 1839.8537 & 1839.1725 & \\
\hline
\end{tabular}

A

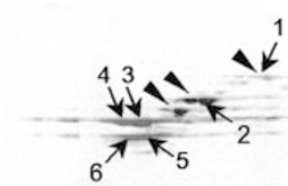

plp3

10

plp3

B $\quad$ RacN17

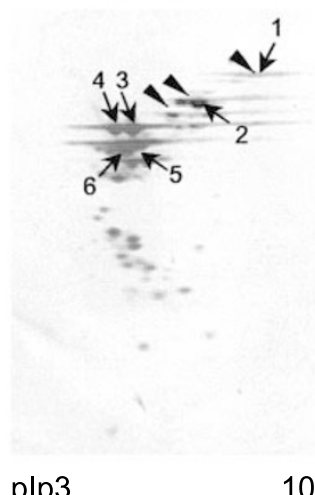

Figure 8 Identification of various vimentins in (A) Rat2 and (B) Rat2-RacN17 cells using antibodies against full vimentin and vimentin head domain. Arrow heads indicate vimentins containing the $\mathrm{N}$-terminal head domain

leads to the question of how RacN17 blocks the activation of SAPK/JNK by heat shock.

Rac1 has been known to regulate a wide variety of cellular processes including actin reorganization, especially membrane ruffles and lamellipodia induced by growth factor or activated Ras. ${ }^{5}$ Previous studies have shown that stress fibers were completely loosened and intermediate filaments aggregated around the nucleus by heat shock, and microtubules were reorganized during recovery, although the actual mechanism of these changes was not known.

To examine how Rac1 causes cellular differences, the differentially expressed proteins in Rat2 and Rat2-RacN17 cells after heat shock were observed using two-dimensional electrophoresis and MALDI-TOF MS. Distinct protein spots on 2D-gel were identified by peptide mapping using MALDITOF MS after in-gel trypsinization. The main difference between the two cell lines was the differential expression of vimentin in Rat2-RacN17 cells. Simultaneously, several vimentin spots were observed and vimentin profile changes proved to be the major difference between Rat-2 and Rat2RacN17 cells and between control and heat-treated cells. Several vimentin spots in $2 \mathrm{D}$ gels can be truncated or phosphorylated forms as mentioned in previous studies. $^{24,25}$ The induction of vimentin spot 1 by heat shock in Rat2 cells (Figure 6C) was negligible in Rat2-RacN17 cells (Figure 6D) and vimentin spots 3, 4, 5 and 6 were overexpressed in Rat2-RacN17 cells (Figure 6B). The modification pattern of each vimentin spot was determined by peptide mapping with MALDI-TOF MS after in-gel digestion and by Western analysis using vimentin antibody and $\mathrm{N}$-terminal head domain specific vimentin antibody. The various spots turned out to be differential truncations of the $\mathrm{N}$-terminus of vimentin. Cellular vimentin changes were also detected with immunofluorescence microscopy. In control Rat2 cells, vimentin collapsed around the nucleus immediately in response to heat shock, penetrated the nucleus, and returned to normal during recovery. In Rat2RacN17 cells, vimentin collapse also occurred immediately after heat shock but recovery of the vimentin network to normal was more rapid without penetration into the nucleus. Recent reports demonstrate that the amino terminus of vimentin is responsible for its DNA binding properties, ${ }^{26}$ and $\mathrm{N}$-terminal vimentin fragments, 28-35, 36-49, 5063 , bind to DNA. ${ }^{27}$ This supports the idea that the vimentin of Rat2-RacN17 cells cannot penetrate into the nucleus in response to heat shock because of the lack of spot 1, intact vimentin. These observations demonstrate that Rac1 plays a key role in the truncation of vimentin by heat shock, although the mechanism should be further studied.

Intermediate filaments are thought to be relatively stable compared with other cytoskeletal components such as actin filaments and microtubules. However, there is increasing evidence that the organization of intermediate filaments is regulated by phosphorylation in various cellular processes. The phosphorylation of serine residues of vimentin by Rho kinase and PKC, and dephosphorylation by type 1 phosphatase, have a definite role in governing regulatory processes in assembly-disassembly and turnover of vimentin filaments at the cleavage furrow during cytokinesis. ${ }^{24}$ PDGF induces reorganization of vimentin filaments by phosphorylation of tyrosine residues, which are controlled by Rac1 and $\mathrm{PI}-3$ kinase. ${ }^{25}$ The relationship between phosphorylation and $\mathrm{N}$-terminal truncation of vimentin by heat shock and the role of Rac1 in this process are not clear. However, one possible hypothesis is that RacN17 inhibits heat shock-induced cell death by interfering with the activation of $\mathrm{PI}$ 3-kinase, which modifies the phosphorylation of vimentin and results in the changed truncation of vimentin. Thus, firstly, Rac1 has been proposed to activate the NADPH oxidase complex, 


\section{Rat2}

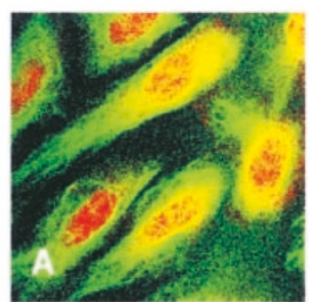

$\mathbf{O} \mathbf{h}$

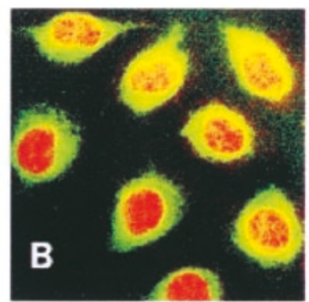

$3 \mathbf{h}$
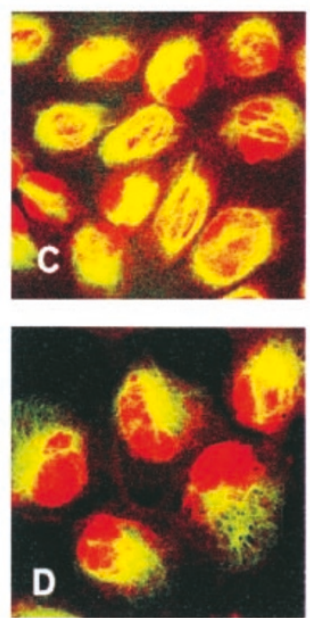

$8 \mathbf{h}$

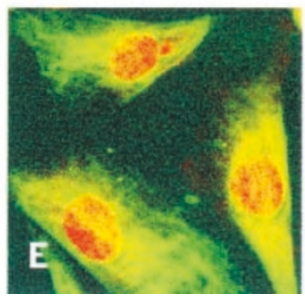

\section{Rat2-Rac N17}
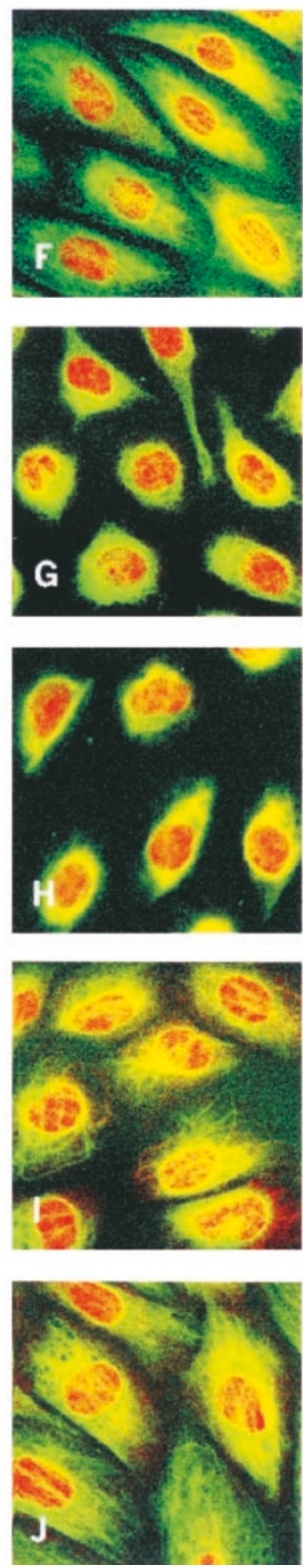

Figure 9 Redistribution of vimentin filaments after heat shock and during recovery. Rat2 $(\mathbf{A}-\mathbf{E})$ and Rat2-RacN17 $(\mathbf{F}-\mathbf{J})$ cells were heated for $20 \mathrm{~min}$ at $45^{\circ} \mathrm{C}$ and allowed to recover for $0,3,8$ and $24 \mathrm{~h}$ at $37^{\circ} \mathrm{C}(\mathrm{B}-\mathrm{E}, \mathrm{G}-\mathrm{J})$. At each time point, cells were fixed with paraformaldehyde and stained with antivimentin and FITC-conjugated rabbit anti mouse antibody. (A) and (F) were control cells

resulting in $\mathrm{H}_{2} \mathrm{O}_{2}$ production. Secondly, the expression of RacN17 inhibited the increase in $\mathrm{H}_{2} \mathrm{O}_{2}$ concentration induced with various growth factors by inhibiting PI 3-kinse activation. ${ }^{28}$ Thirdly, heat shock stimulates c-Src and PI 3kinase in a time dependent manner. ${ }^{29}$ Studies are underway in our laboratory to test this hypothesis.

Two lines of evidence indicate that Rac1 acts as a key molecule in response to heat shock by modulating vimentin reorganization. First, Rat2-RacN17 cells having a Rac1

negative mutant were thermotolerant even though the hsp response was similar to control Rat2 cells. Second, Rat2RacN17 cells repaired vimentin reorganization faster, and caused lower SAPK/JNK activation in response to heat shock, than control cells. Although the signal transduction pathways of vimentin reorganization are still poorly understood, Rac1 plays an important role in heat shock signaling by modification of vimentin. The identification of vimentin modification in heat shock may provide clues to how Rac1 impinges upon heat shock signaling and other systems as well.

\section{Materials and Methods}

\section{Cell cultures}

Rat2 fibroblast cells were obtained from the American Type Culture Collection (ATCC, CRL 1764). Rat2 clones with stable expression of RacN17 were prepared by co-transfecting pEXV-RacN17 plasmid with pSV-Neo plasmid followed by a selection of clones in the presence of G418 antibiotics for $2-3$ weeks as described previously. ${ }^{30}$ Cells were grown in Dulbecco's modified Eagle's medium (DMEM) supplemented with $2 \mathrm{mM}$ glutamine, $10 \%(\mathrm{v} / \mathrm{v})$ fetal bovine serum (FBS) and gentamycin at $37^{\circ} \mathrm{C}$ in an atmosphere of $5 \% \mathrm{CO}_{2}-95 \%$ air. Several clones were tested and typical reproducible clones were used for the experiments. All experiments were performed on $50 \%$ or less confluent cell cultures. For the heat treatments, monolayers of cells grown in tissue culture dishes were incubated at $45 \pm 0.1^{\circ} \mathrm{C}$ in a water bath.

\section{Cell death measurements}

Cell viability was assessed by using modified SRB assay and flow cytometric analysis after propidium iodide $(\mathrm{PI})$ staining. In flow cytometric analysis, cells treated with heat shock were trypsinized and harvested. They were fixed in $70 \%$ ethanol and stored at $4{ }^{\circ} \mathrm{C}$ overnight or longer. Following centrifugation, cells were stained with $\mathrm{PI}$ solution ( $50 \mu \mathrm{g} / \mathrm{mL} \mathrm{PI}, 250 \mu \mathrm{g} / \mathrm{mL}$ RNase in PBS) and incubated at $37^{\circ} \mathrm{C}$ for $5 \mathrm{~h}$. Cells were analyzed using a Becton Dickinson FACSCalibur flow cytometer (San Jose, CA, USA).

\section{Profiling of protein synthesis by ${ }^{35} \mathrm{~S}$-methionine pulse labeling}

Patterns of cellular protein synthesis after heat shock were examined by pulse labeling with ${ }^{35} \mathrm{~S}$-methionine $(1 \mu \mathrm{Ci} / \mathrm{mL})$ in methionine free DMEM media for $1 \mathrm{~h}$. The labeled proteins were separated on one- or two-dimensional SDS-PAGE gels, detected and quantified by BAS2500 (Fujiphotofilm Co. Ltd., Tokyo, Japan).

\section{SAPK/JNK assay}

SAPK/JNK activities were assayed using glutathione-S-transferase(GST)-c-Jun 1-89 peptide (provided by Dr. JR Woodgett) as a substrate after immunoprecipitation with anti-JNK antibody (Santa Cruz Biotechnology). Cell pellets were homogenized with buffer $A$ containing $20 \mathrm{mM}$ HEPES, pH 7.4, $50 \mathrm{mM} \beta$-glycerophosphate, $2 \mathrm{mM}$ EGTA, $1 \mathrm{mM}$ dithiothreitol, $1 \mathrm{mM} \mathrm{Na} \mathrm{VO}_{4}, 1 \%$ Triton $\mathrm{X}-100,10 \%$ glycerol, $2 \mu \mathrm{M}$ leupeptin, $400 \mu \mathrm{M}$ phenylmethylsulfonyl fluoride, and 10 units $/ \mathrm{mL}$ aprotinin. The supernatant containing $1 \mathrm{mg}$ of protein was incubated with antibodies against mammalian SAPK/JNK and then with protein A-Sepharose 4B suspension. The immunocomplexes 
were washed three times and incubated with kinase buffer $(50 \mathrm{mM}$ Tris-Cl, $\mathrm{pH} 7.4,10 \mathrm{mM} \mathrm{MgCl}$, 2 mM EGTA, $1 \mathrm{mM}$ DTT, 0.1\% Triton $\mathrm{X}-100)$ supplemented with GST-C-Jun, $\left[\gamma^{3}{ }^{32} \mathrm{P}\right] \mathrm{ATP}$, and $\mathrm{MgCl}_{2}$ for $20 \mathrm{~min}$ at $37^{\circ} \mathrm{C}$. To stop the reaction, $2 \times$ gel sample buffer was added. Samples were subjected to $10 \%$ SDS-PAGE and the gels were stained, destained and dried. Phosphorylation of GST-C-Jun was measured by BAS2500.

\section{Activation of procaspase-3 and caspase-3 activity: poly(ADP-ribose) polymerase (PARP) cleavage and immunoblotting}

Cells exposed to various stresses were lysed in $2 \times$ gel sample buffer. Samples containing $100 \mu \mathrm{g}$ protein were separated by $8 \%$ SDSpolyacrylamide gel electrophoresis and transferred to nitrocellulose membranes. Procaspase- 3 was detected wih polyclonal antiserum (Santa Cruz Biotechnology, 1:1000) and PARP with monoclonal antibody (Biomol, 1:10000) and alkaline phosphatase-conjugated secondary antibody and detected with enhanced chemiluminescence (ECL, Amersham) and LAS1000 (Fujiphotofilm Co. Ltd., Tokyo, Japan).

\section{Immunofluorescence microscopy}

For morphological studies, cells were treated with heat shock at $45^{\circ} \mathrm{C}$ for various lengths of time, fixed with $3.7 \%$ formaldehyde for $10 \mathrm{~min}$, and permeabilized with $0.1 \%$ Triton $\mathrm{X}-100$ for $5 \mathrm{~min}$. Actin cytoskeleton was stained by incubation with $1 \mu \mathrm{M}$ FITC-conjugated phalloidin (Sigma) for $1 \mathrm{~h}$ followed by three washes with phosphate buffered saline. Images of cells were observed and photographed using a Meridian confocal microscope.

For immunofluorescence studies, cells were grown on coverslips for $48 \mathrm{~h}$, gently rinsed in HBSS, and fixed with $4 \%$ paraformaldehyde in HBSS for 10 min at room temperature. ${ }^{31}$ After washing with HBSS, the cells were permeabilized by incubating with $0.1 \%$ Triton $X-100$ in HBSS for $10 \mathrm{~min}$ at room temperature before immunostaining. Nonspecific protein absorption was inhibited by incubation of the cells for $1 \mathrm{~h}$ in HBSS containing 3\% BSA, $0.2 \%$ Tween 20 , and $0.2 \%$ gelatin. For vimentin, cells were incubated with mouse vimentin antibody (Santa Cruz Biotechnology, Inc.) diluted at 1:100 in HBSS containing $1 \%$ sucrose and $1 \% \mathrm{BSA}$ for $2 \mathrm{~h}$ at $37^{\circ} \mathrm{C}$. After three washes with HBSS, cells were incubated for $1 \mathrm{~h}$ with FITC-conjugated rabbit antimouse (Jackson ImmunoResearch Laboratories) diluted at 1:50 and subsequently washed with HBSS. DNA was stained with $1 \mu \mathrm{g} / \mathrm{mL}$ propidium iodide at room temperature. Confocal microscopy was performed with a Multi-photon Radiance 2000 (Bio-Rad) connected to a microscope (Nikon Eclipse TE 300).

\section{Analysis of tryptic peptides after in-gel digestion of 2D-PAGE spots by MALDI-TOF mass spectometry}

The cellular proteins were separated on two-dimensional gel electrophoresis and stained with coomassie blue or metabolically labeled proteins were detected with autoradiography using BAS2500 (Fujiphotofilm Co. Ltd., Tokyo, Japan). After visualization, the gel spots were excised with a scalpel and placed in an eppendorf tube. The protocol used for the in-gel digest was a modified method described previously. ${ }^{32,33}$ The gels were crushed and destained by washing with $30 \%$ methanol for 10 min until the gel spots were cleared. The gels were dehydrated by addition of acetonitrile and rehydrated by adding $10 \mu \mathrm{L}$ of $20 \mathrm{mM}$ ammonium bicarbonate containing $0.01 \mu \mathrm{g} / \mu \mathrm{L}$ of sequencing grade trypsin. The rehydrated gels for trypsin hydrolysis were incubated at $37^{\circ} \mathrm{C}$ for $12-15 \mathrm{~h}$.
Digested peptides were extracted three times by adding $30 \mu \mathrm{L}$ of acetonitrile/0.1\% TFA $(1: 1 \mathrm{v} / \mathrm{v})$ solution first, then by adding $20 \mu \mathrm{L}$ of acetonitrile. Pooled extracted solutions were evaporated to dryness in a Speed vacuum concentrator.

Each sample was dissolved in $2 \mu \mathrm{L}$ of acetonitrile/0.1\% TFA (1:1 v/ v). Aliquots of $1 \mu \mathrm{L}$ were mixed with $1 \mu \mathrm{L}$ of saturated matrix solution ( $\alpha$-cyano-4-hydroxycinnamic acid in acetonitrile/0.1\% TFA (1:1 v/v)) and were applied to the probe. The mass spectrometric analysis was performed with Applied Biosystems (Voyager-Elite Biospectrometry Workstation, Applied Biosystems, Inc., Fremingham, MA, USA) MALDI-TOF MS using a nitrogen laser $(337 \mathrm{~nm})$ with delayed extraction. The extraction voltage was $20 \mathrm{kV}$. For interpretation of the mass spectra of protein digests, we used the MS-Fit program available at the World Wide Web site of the University of California at San Francisco (http://prospector.ucsf.edu/).

\section{Acknowledgements}

We thank Dr. James R Woodgett for providing GST-c-jun 1-89/pGex-2T plasmid and Dr. M Inagaki for antibody against head domain of vimentin. We thank Dr. HJ Kim in Hyundai Pharm.Ind. Co. for letting us to use MALDI-TOF MS. This work was supported by KOSEF through the Center for Cell Signaling Research (CCSR) at Ewha Womans University and by the Research fund for Womans University (KISTEP, 1998). Students (S-Y Lee, EJ Song, H-J Kim, H-J Kang) were financially supported by Brain Korea 21 program.

\section{References}

1. Parsell DA and Linquist S (1993) The function of heat-shock proteins in stress tolerance: degradation and reactivation of damaged proteins. Annul. Rev. Genet. 27: $427-496$

2. Park J-E, Lee K-J and Kim C (1998) Thermotolerance inhibits various stressinduced apoptosis in NIH3T3 cells. Arch. Pharm. Res. 21: 46-53

3. Mosser DD, Caron AW, Bourget L, Meriin AB, Sherman MY, Morimoto RI and Massie $B(2000)$ The chaperone function of hsp70 is required for protection against stress-induced apoptosis. Mol. Cell. Biol. 20: 7146-7159

4. Minowada G and Welch WJ (1995) Clinical implications of the stress response. J. Clin. Invest. 95: 3-12

5. Hall A (1994) Small GTP-binding proteins and the regulation of the actin cytoskeleton. Annu. Rev. Cell Biol. 10: 31-54

6. Abo A, Pick E, Hall A, Totty N, Teahan CG and Segal AW (1991) Activation of the NADPH oxidase involves the small GTP-binding protein p21rac1. Nature 353: $668-670$

7. Hill CS, Wynne J and Treisman R (1995) The Rho family GTPases RhoA, Rac1, and $\mathrm{CDC} 42 \mathrm{Hs}$ regulate transcriptional activation by SRF. Cell 81: $1159-1170$

8. Coso OA, ChiarielloM, YuJC, Teramoto H, Crespo P, Xu N, Miki T and Gutkind JS (1995) The small GTP-binding proteins Rac1 and Cdc42 regulate the activity of the JNK/SAPK signaling pathway. Cell 81: 1137-1146

9. Minden A, Lin A, Claret FX, Abo A and Karin M (1995) Selective activation of the JNK signaling cascade and c-Jun transcriptional activity by the small GTPases Rac and Cdc42Hs. Cell 81: 1147-1157

10. Sulciner DJ, Irani K, Yu ZX, Ferrans VJ, Goldschmidt CP and Finkel T (1996) Rac1 regulates a cytokine-stimulated, redox-dependent pathway necessary for NF- $\kappa$ B activation. Mol. Cell Biol. 16: 7115-7121

11. Seger R and Krebs EG (1995) The MAPK signaling cascade. FASEB J. 9: 726 735

12. Kyriakis JM and Avruch J (1996) Protein kinase cascades activated by stress and inflammatory cytokines. BioEssays 18: $567-577$

13. Evers EE, van der Kammen RA, ten Klooster JP and Collard JG (2000) Rho-like GTPases in tumor cell invasion. Methods Enzymol. 325: 403-415

14. Olson MF, Ashworth A and Hall A (1995) An essential role for Rho, Rac, and Cdc42 GTPases in cell cycle progression through G1. Science 269: 1270-1272 
15. Kim BC, YiJY, YiSJ, Shin IC, Ha KS, Jhun BH, Hwang SB and Kim JH (1998) Rac GTPase activity is essential for EGF-induced mitogenesis. Mol. Cells 8: 90-95

16. Brenner B, Koppenhoefer U, Weinstock C, Linderkamp O, Lang F and Gulbins $E$ (1997) Fas- or ceramide-induced apoptosis is mediated by a Rac1-regulated activation of Jun N-terminal kinase/p38 kinases and GADD153. J. Biol. Chem. 272: $22173-22181$

17. Kawazoe N, Watabe M, Masuda Y, Nakajo S and Nakaya K (1999) Tiam1 is involved in the regulation of bufalin-induced apoptosis in human leukemia cells. Oncogene 18: 2413-2421

18. Chan WH, Yu JS and Yang SD (1998) Heat shock stress induces cleavage and activation of PAK2 in apoptotic cells. J. Protein Chem. 17: 485-494

19. Ozaki M, Deshpande SS, Angkeow P, Suzuki S and Irani K (2000) Rac1 regulates stress-induced, redox-dependent heat shock factor activation. J. Biol. Chem. 275: 35377-35383

20. ZankeBW, Boudreau K, Rubie E, WinnettE, Tibbles LA, Zon L, Kyriakis J, Liu F-F and Woodget JR (1996) The stress-activated protein kinase pathway mediates cell death following injury induced by cis-platinum, UV irradiation or heat. Curr. Biol. 6: 606-613

21. Gabai VL, Meriin AB, MosserDD, Caron AW, Rits SO, Shifrin VI and Sherman MY (1997) Hsp70 prevents activation of stress kinases. J. Biol. Chem. 272: 1803318037

22. Mosser DD, Caron AW, Bourget L, Denis-Larose C and Massie B (1997) Role of the human heat shock protein hsp70 in protection against stress-induced apoptosis. Mol. Cell. Biol. 17: 5317-5327

23. Kim HJ and Lee K-J (2000) Heat shock and ceramide have different apoptotic pathways. Mol. Cell. Biochem. submitted

24. Inada H, Togashi H, Nacamura Y, Kaibuchi K, Nagata K and Inagaki M (1999) Balance between activities of Rho kinase and type 1 protein phosphatase modulates turnover of phosphorylaion and dynamics of desmin/vimentin filaments. J. Biol. Chem. 274: 34932-34939
25. Valgeirsdottir S, Claesson-Welsh L, Bongcam-Rudolff E, Heilman U, Westermark B and Heldin C (1998) PDGF induces reorganization of vimentin filaments. J. Cell Sci. 111: 1973-1980

26. Shoeman RL, Hartig R and Traub P (1999) Characterization of the nucleic acid binding region of the intermediate filament protein vimentin by fluorescence polarization. Biochemistry 38: 12802-12809

27. Wang Q, Shoeman Rand Traub P (2000) Identification of the amino acid residues of the amino terminus of vimentin responsible for DNA binding by enzymatic and chemical sequencing and analysis by MALDI-TOF. Biochemistry 39: 66456651

28. Bae YS, Sung J-Y, Kim O-S, Kim YJ, Hur KC, Kazlauskas A and Rhee SG (2000) Platelet-derived growth factor-induced $\mathrm{H}_{2} \mathrm{O}_{2}$ production requires the activation of phosphatidylinositol 3-kinase. J. Biol. Chem. 275: 10527-10531

29. Lin RZ, Hu Z-W, Chin JH and Hoffman BB (1997) Heat shock activates c-Src tyrosine kinases and phosphatidylinositol 3-kinase in NIH3T3 fibroblasts. J. Biol. Chem. 272: 31196-31202

30. Kim JH, Johansen FE, Robertson N, Catino JJ, Prywes R and Kumar CC (1994) Suppression of Ras transformation by serum response factor. J. Biol. Chem. 269: $13740-13743$

31. Pinon VP, Millot G, Munier A, Vassy J, Linares-Cruz G, Capeau J, Calvo F and Lacombe ML (1999) Cytoskeletal association of the A and B nucleoside diphosphate kinases of interphasic but not mitotic human carcinoma cell lines: specific nuclear localization of the B subunit. Exp. Cell. Res. 246: 355-367

32. Sechi S and Chait BT (1998) Modification of cysteine residues by alkylation. A tool in peptide mapping and protein identification. Anal. Chem. 70: 5150-5158

33. Song EJ, Kim YS, Chung JY, Kim E, Chae S-K and Lee K-J (2000) Oxidative modification of nucleoside diphosphate kinase and its identification by MALDITOF MS. Biochemistry 39: 10090-10097 